\title{
Lung cancer mortality in a cohort of workers employed at a cadmium recovery plant in the United States: an analysis with detailed job histories
}

\author{
Tom Sorahan, Robert J Lancashire
}

\begin{abstract}
Objectives-To identify and measure any relations between occupational exposure to cadmium compounds (oxide, sulphide, and sulphate) and the risk of mortality from lung cancer.

Methods-The mortality experience of 571 male production workers from a cadmium recovery facility in the United States was investigated for the period 1940-82. All study subjects were first employed in the period 1926-69; they had all been employed for at least six months between 1 January 1940 and 31 December 1969. Newly abstracted detailed job histories for the period 1926-76 were combined with assessments of exposures to cadmium over time to develop individual estimates of cumulative exposure to cadmium (total exposure and exposures received both in the presence and absence of "high" exposures to arsenic trioxide). Poisson regression was used to investigate risks of mortality from lung cancer in relation to four concentrations of cumulative exposure to cadmium $(<400,400-999$, 1000-1999, > $2000 \mathrm{mg} \cdot \mathrm{m}^{-3}$.days).
\end{abstract}

Results-After adjustment for age attained, year of hire, and Hispanic ethnicity, there was a significant positive trend $(P<0.05)$ between cumulative exposure to cadmium and risks of mortality from lung cancer. Relative to a risk of unity for the lowest exposure category (first level), risks were $2 \cdot 30$ (95\% confidence interval (95\% CI) 0.72 to $7 \cdot 36), 2.83$ $(95 \%$ CI 0.75 to 10.72$)$, and $3.88(95 \%$ CI 1.04 to 14.46 ) for the second, third, and fourth categories, respectively. Similar findings were obtained after adjustment for age only. Trends were more pronounced when employment histories were lagged first by 10 years and then by 20 years. A separate analysis examined the independent effects of exposure to cadmium received in the presence of high exposures to arsenic trioxide (mainly cadmium oxide) and exposures to cadmium received without such exposure to arsenic (mainly cadmium sulphide and cadmium sulphate). A significant trend for a risk of lung cancer was found only for exposures to cadmium received in the presence of arsenic trioxide.

Conclusions-Hypotheses which are consistent with the study findings include: $(a)$ cadmium oxide in the presence of arsenic trioxide is a human lung carcinogen, (b) cadmium oxide and arsenic trioxide are human lung carcinogens and cadmium sulphate and cadmium sulphide are not (or they are less potent carcinogens), or (c) arsenic trioxide is a human lung carcinogen and cadmium oxide, cadmium sulphate, and cadmium sulphide are not. There were only 21 deaths from lung cancer available for this analysis and it is impossible to gauge which, if any, of these hypotheses are correct.

(Occup Environ Med 1997;54:194-201)

Keywords: cadmium; arsenic; lung cancer

Cancer mortality among workers from a United States cadmium recovery plant has been investigated by several author ${ }^{1-6}$ and the two most recent reports, ${ }^{56}$ which reached very different conclusions about risks of lung cancer after occupational exposure to cadmium, were reviewed by Doll in $1992 . .^{7}$ This review noted that "these studies are of greater interest than the size of the cohort might imply, because of the detailed data that the investigators were able to secure about the levels of cadmium to which the workers were exposed". In 1993, a Working Group of the International Agency for Research on Cancer (IARC) published a monograph on the evaluation of carcinogenic risks to humans after exposure to cadmium and cadmium compounds. ${ }^{8}$ The Working Group concluded that "There is sufficient evidence in humans for the carcinogenicity of cadmium and cadmium compounds' and the overall evaluation was that "Cadmium and cadmium compounds are carcinogenic to humans (Group 1)". The significant positive trends for risk of lung cancer with estimated cumulative exposure to cadmium reported both by Thun et $a l^{3}$ and Stayner et $a l^{5}$ in their analyses of the mortality experience of workers from the United States cadmium recovery plant were clearly key components of the sufficient evidence referred to by the working group.

In 1994 , a short report ${ }^{9}$ highlighted two problems, possibly serious, about the quality of the data on job histories collected by Thun et $a l^{3}$ under the auspices of the National Institute of Occupational Safety and Health (NIOSH). The estimated cumulative exposures to cadmium derived from these data were also used by Stayner et $a l^{5}$ and Lamm et $a l^{6}$ in their analyses of lung cancer mortality in this cohort. The problems with the data on job his- 
tories arose from the use of sparse information contained in summary personnel records rather than making use of the extraordinarily detailed information on job histories contained in time sheet books (about 60 books, each 10 inches thick). The collection of data on job histories in terms of departments rather than the general work areas defined by Thun et $a l^{3}$ becomes vitally important when adjusting for any effects of arsenic; exposure to arsenic compounds being much higher in departments involved in the early stages of the cadmium process. Stayner et al concluded that it is "impossible to fully discount the potential influence of exposure to arsenic" on the doseresponse relation which they had found between risk of lung cancer and cumulative exposure to cadmium, and that "more detailed information would be required to fully evaluate potential confounding by arsenic". ${ }^{5}$ In an attempt to rectify these issues, the analysis presented in this report makes use of detailed job histories newly abstracted from the time sheet records.

\section{Materials and methods}

FACTORY PROCESSES

The plant operated as a lead smelter from 1896 to 1919 , then as an arsenic smelter from 1920 to 1925, and finally as a cadmium recovery plant from 1926 onwards. In this last period, the plant's primary function was to extract cadmium from the fines (precipitated dusts) obtained as a byproduct of pollution control at lead, zinc, and other non-ferrous smelters. The incoming fines were sampled and then roasted (or "fumed off") in Godfrey roasters and the condensed dusts collected in a baghouse. These materials were then mixed with sulphuric acid to form an acid cake which was then calcined. The resulting calcine was dissolved in sulphuric acid and purified by precipitation and filtration (solution department) before electroplating cadmium out of the final solution in an electrolytic refinery (tankhouse department). Sheets of cadmium metal were stripped off the cathode, melted, and cast into bricks or other shapes (casting department). High purity cadmium oxide was manufactured by oxidation in gas fired retorts (retort department) and any residue was dissolved in sulphuric acid and treated with hydrogen sulphide to produce cadmium sulphide pigment (pigment department). Each of the above processes was carried out in a separate building or a separate section of a building. Flow sheets describing these factory processes have been provided previously. ${ }^{210}$

\section{STUDY COHORT AND FOLLOW UP}

Computerised information relating to identifying particulars, follow up details complete to the end of 1982, and job histories developed by the original NIOSH investigators were provided (SH Lamm, personal communication) for 597 of the 602 white male workers described by Thun et al. ${ }^{3}$ These workers were employed for at least six months as plant production workers in the period 1 January 1940-31 December 1969. Some double checking of the completeness of the computerised mortality data was possible because copies of death certificates and other study

Table 1 Comparison of data on job histories (105 443 man-half-months of employment) newly abstracted from time sheets (29 job and department categories) with NIOSH data on job histories seven general work categories), 1926-76

\begin{tabular}{|c|c|c|c|c|c|c|c|c|}
\hline \multirow[b]{2}{*}{ New data on job histories } & \multicolumn{7}{|l|}{ NIOSH data } & \multirow[b]{2}{*}{ Total } \\
\hline & $\begin{array}{l}1 \\
\text { Departments with } \\
\text { high cadmium } \\
\text { exposure }\end{array}$ & $\begin{array}{l}2 \\
\text { Production } \\
\text { foreman }\end{array}$ & $\begin{array}{l}3 \\
\text { Office } \\
\text { laboratory }\end{array}$ & $\begin{array}{l}4 \\
\text { Plant } \\
\text { maintenance }\end{array}$ & $\begin{array}{l}5 \\
\text { Shop } \\
\text { maintenancet }\end{array}$ & $\begin{array}{l}6 \\
\text { Guard, } \\
\text { janitor }\end{array}$ & $\begin{array}{l}7 \\
\text { Solution } \\
\text { tankhouse, } \\
\text { pigment }\end{array}$ & \\
\hline 1 Foreman & 635 & 7322 & 0 & 252 & 0 & 15 & 96 & 8320 \\
\hline 2 Calcine & 7882 & 9 & 0 & 500 & 0 & 0 & 401 & 8792 \\
\hline 3 Mixer and screener & 2246 & 0 & 0 & 20 & 0 & 10 & 101 & 2377 \\
\hline 4 Solution (operator and pressman) & 3854 & 29 & 0 & 39 & 0 & 26 & 2417 & 6365 \\
\hline 5 Solution (charger) & 2090 & 13 & 0 & 25 & 0 & 2 & 1048 & 3178 \\
\hline 6 Pigment (gasman) & 547 & 0 & 0 & 24 & 0 & 0 & 33 & 604 \\
\hline 7 Pigment (other operator) & 1438 & 105 & 0 & 47 & 0 & 6 & 69 & 1665 \\
\hline 8 Tankhouse and electrolytic & 8019 & 136 & 0 & 322 & 0 & 103 & 9782 & 18362 \\
\hline 9 Retort & 3359 & 38 & 0 & 36 & 0 & 4 & 243 & 3680 \\
\hline 10 Caster & 6948 & 27 & 0 & 128 & 0 & 3 & 312 & 7419 \\
\hline 11 Weigher and packer & 2889 & 2 & 0 & 73 & 0 & 19 & 276 & 3259 \\
\hline 12 Indium & 801 & 3 & 0 & 57 & 0 & 0 & 104 & 965 \\
\hline 13 Acid recovery & 2298 & 0 & 0 & 9 & 0 & 1 & 1040 & 3348 \\
\hline 14 Loading gang & 464 & 0 & 0 & 24 & 0 & 0 & 39 & 527 \\
\hline 15 Concentrated and dry dust $\ddagger$ & 345 & 0 & 0 & 19 & 0 & 0 & 7 & 371 \\
\hline 16 General labourer (unloading) & 2050 & 0 & 0 & 431 & 119 & 114 & 430 & 3144 \\
\hline 17 Sampling & 841 & 0 & 0 & 163 & 0 & 0 & 13 & 1017 \\
\hline 18 Crushing & 444 & 0 & 0 & 4 & 0 & 1 & 7 & 458 \\
\hline 19 Roasting & 2399 & 3 & 0 & 163 & 0 & 11 & 62 & 2638 \\
\hline 20 Lead & 1553 & 4 & 0 & 236 & 3 & 15 & 178 & 1989 \\
\hline 21 Thallium & 341 & 0 & 0 & 18 & 0 & 239 & 23 & 621 \\
\hline 22 Machine shop & 192 & 1436 & 0 & 3610 & 1301 & 0 & 49 & 6588 \\
\hline 23 Maintenance (plant) & 872 & 3 & 0 & 3748 & 4 & 4 & 169 & 4800 \\
\hline 24 Electrical shop & 24 & 0 & 0 & 1326 & 0 & 0 & 0 & 1350 \\
\hline 25 Welder and burner & 28 & 0 & 0 & 1622 & 0 & 0 & 23 & 1673 \\
\hline 26 Carpenter & 202 & 0 & 0 & 2556 & 319 & 132 & 132 & 3341 \\
\hline 27 Auto truck & 675 & 0 & 0 & 70 & 0 & 230 & 2445 & 3420 \\
\hline 28 Janitor, laundry, guard & 796 & 9 & 130 & 94 & 0 & 2619 & 1077 & 4725 \\
\hline 29 Arsenic & 351 & 2 & 0 & 62 & 0 & 0 & 0 & 415 \\
\hline Unclassifiable & 29 & 0 & 0 & 3 & 0 & 0 & 2 & 34 \\
\hline Total & 54613 & 9141 & 130 & 15681 & 1746 & 3554 & 20578 & 105443 \\
\hline
\end{tabular}

*Defined as production work in sampling, roasting and baghouse, mixing, calcine, foundry (casting), retort. In the time sheet data, this grouping would include mixer and screener, concentrated and dry dust, and crushing.

†Repair shops.

$\ddagger$ Includes baghouse. 
materials analysed by $\operatorname{Varner}^{2}$ had been provided by the company; no inconsistencies were found. The analysis was restricted to those 571 male workers first employed after 1 January 1926. The cohort was relatively old (date of birth: $<1890, \mathrm{n}=9 ; 1890-99, \mathrm{n}=$ $32 ; 1900-09, \mathrm{n}=111 ; 1910-19, \mathrm{n}=184$; $1920-29, \quad \mathrm{n}=154 ; \quad 1930-39, \quad \mathrm{n}=54$; $1940-49, \mathrm{n}=27$ ).

\section{ABSTRACTION OF JOB HISTORIES}

The time sheet records, still available for the period 1926 onwards, show how many hours each day each worker spent in different jobs. (The time sheet records had been microfilmed by the original NIOSH researchers but were not used in the development of their files on job histories. ${ }^{3}$ ) Most sheets refer to a half month (one sheet for the 1st-15th of the month and another for the rest) although for some years sheets refer to a whole month. These records had been collected because workers were paid on the basis of hours worked, with different jobs attracting different rates of pay. (For example, in 1948 a calcine department workman received US $\$ 1 \cdot 1825$ per hour whereas a solution operator received US $\$ 1 \cdot 1255$ per hour.)

The starting point for the new data abstraction was a job dictionary compiled from some 300 job titles found in microfilm 27, relating to time sheet records for the period AprilAugust 1949. ${ }^{9}$ These job titles had been categorised by company personnel into one of 22 departments listed previously. ${ }^{9}$ In the course of further data abstraction new titles were found and, periodically, unclassified job titles were sent to company personnel for categorisation. The final job dictionary comprised some 600 job titles classified under one of 29 headings (first column, table 1 ). This job dictionary was used by two survey assistants to abstract, from the microfilmed time sheets, the principal job and department for each cohort member for each half month. The principal job and department was selected as that in which the most hours were worked (principal job and departments accounted for $91 \%$ of all hours worked by cohort members in AprilAugust $1949^{\circ}$ and $95 \%$ of all hours worked by cohort members in June-December 1972). (Abstraction of these data took some four person-years of effort.)

Employment histories were abstracted for the period 1926-76. Data for several periods were unavailable from the microfilmed records (March-April 1946; January-July 1952; JulyDecember 1967; January-March 1968). The time sheet books and service record cards were, therefore, reviewed at the plant. Data for the missing period in 1952 were, in fact, available and relevant data were abstracted. The remaining missing periods were found to relate to labour strikes.

The abstracted data were entered into computer files and compared with job histories collected by NIOSH investigators. Inconsistencies in the timing of employments were reviewed with source data at the plant and a few job entries in the newly abstracted data were found to relate to other people with the same name as study subjects. These job entries were removed from the file. There were a further 5904 man-half-months of employment in the NIOSH database for which no principal department was available in the new database. This difference was explained, almost entirely, by labour strikes, holidays, and sickness absence. Also, there were a further 1046 man-half-months of employment in the new database for which there were no corresponding entries in the NIOSH database. This small difference (in percentage terms) seemed to be due to abstraction errors in the NIOSH database.

For a total of 105443 man-half-months of employment, a useful comparison could be made between the original NIOSH data on job histories (defined as seven general work categories), and the newly abstracted data on job histories (defined as 29 jobs and departments). Table 1 shows the results of cross classifying each of these man-half-months according to the NIOSH database and the new database; errors of misclassification were very different for different departments. For example, of the 8792 man-half-months of employment in the calcine department (new database), 7882 $(89.6 \%)$ had been placed by Thun et $a l^{3}$ in "general work category 1" (which comprised the calcine and five other high exposure departments), whereas of the 18362 manhalf-months of employment in the tankhouse department (new database) only 9782 $(53.3 \%)$ had been placed in the "solution/ tankhouse/pigment" category. Even lower percentages apply to other types of work, including solution $((2417+1048) /(6365+3178)=$ $36 \cdot 3 \%)$ and pigment $((69+33) /(1665+604)$ $=4.5 \%)$ departments. There is no suitable category for some departments in the NIOSH scheme. The lead department (unconnected with the cadmium process) would be one such department and of the 1989 man-half-months of employment shown under this heading in the new database, $1553(78 \cdot 1 \%)$ had been placed in general work category 1 (high exposure to cadmium) in the NIOSH database.

\section{ESTIMATION OF CUMULATIVE EXPOSURES TO} CADMIUM

Cadmium exposures from inhalation associated with working in 10 different departments in five different periods have been estimated by Smith et al. ${ }^{10}$ Consideration had been given to 1367 area measurements (static samples) carried out in the period 1943-76 (560 of these measurements related to the period 1970-6). Also, the relation between area and personal sampling data in the period 1973-6 had been examined ( 560 area samples and 58 personal samples), and the results of a separate study into the effectiveness of personal respirators were considered. ${ }^{1}$ The job exposure matrix (table 2) includes estimates of cadmium exposures from inhalation for a further two department groupings (non-production and non-plant). ${ }^{12}$ The estimates, provided in the job exposure matrix, of exposure to cadmium from inhalation do not all refer to cad- 
Table 2 Estimates of cadmium exposures by inhalation $\left(\mathrm{mg} / \mathrm{m}^{3}\right)$ by department *

\begin{tabular}{llllll}
\hline \multirow{2}{*}{ Plant department } & \multicolumn{2}{l}{ Time period } & & \\
\cline { 2 - 6 } & Before 1950 & $1950-4$ & $1955-9$ & $1060-4$ & $1965-76$ \\
\hline Sampling & 1.0 & 0.6 & 0.6 & 0.6 & 0.6 \\
Roaster & 1.0 & 0.6 & 0.6 & 0.6 & 0.6 \\
Mixing & 1.5 & 0.4 & 0.4 & 0.4 & 0.4 \\
Calcine & 1.5 & 1.5 & 1.5 & 0.4 & 0.15 \\
Solution & 0.8 & 0.8 & 0.4 & 0.4 & 0.04 \\
Tankhouse & 0.04 & 0.04 & 0.04 & 0.02 & 0.02 \\
Foundry & 0.8 & 0.1 & 0.1 & 0.1 & 0.04 \\
Retort & 1.5 & 0.2 & 0.2 & 0.2 & 0.2 \\
Pigment & 0.2 & 0.2 & 0.04 & 0.04 & 0.04 \\
Non-production & 0.09 & 0.05 & 0.04 & 0.024 & 0.02 \\
Office and laboratories & 0.005 & 0.004 & 0.004 & 0.003 & 0.003 \\
Non-plant & 0.09 & 0.05 & 0.04 & 0.04 & 0.02 \\
\hline
\end{tabular}

${ }^{\star}$ From Smith et al ${ }^{10}$ and Ellis et al. ${ }^{12}$

Table 3 Cross classification of departments assessed in job exposure matrix ${ }^{10} 12$ with job and departments identified from time sheets

\section{Plant department}

assessed in

job exposure matrix

Principal job and department from time sheet data ${ }^{\star}$

\begin{tabular}{ll}
\hline Sampling & Sampling \\
Roaster & Roasting, concentrated and dry dust, crushing, arsenic, welder and \\
burner & Mixer and screener \\
Mixing & Calcine \\
Calcine & Solution (operator and pressman), solution (charger) \\
Solution & Tankhouse and electrolytic \\
Tankhouse & Caster \\
Foundry & Retort \\
Retort & Pigment (gasman), pigment (other operator) \\
Pigment & Weigher and packer, auto truck, indium, acid recovery, lead, thallium, \\
Non-production & loading gang, general labourer (unloading), machine shop, electrical \\
& shop, carpenter \\
Non-plant & Janitor, laundry, guard
\end{tabular}

*For the remaining three categories (foreman, maintenance (plant), unclassifiable) the following scheme was adopted. For each period (table 2) the mean was calculated of all departmental scheme was adopted. For each period (table 2) the mean was calculated of all departmental
estimates (ignoring the non-plant category) weighted by the number of man-months estimates (ignoring the non-plant category) weighted by the number of man-months
of employment for each department. The resulting exposure estimates were: before 1950 $0.53 \mathrm{mg} / \mathrm{m}^{3} ; 1950-4,0.34 \mathrm{mg} / \mathrm{m}^{3} ; 1955-9,0.29 \mathrm{mg} / \mathrm{m}^{3} ; 1960-4,0.17 \mathrm{mg} / \mathrm{m}^{3} ; 1965-76$, $0.10 \mathrm{mg} / \mathrm{m}^{3}$.
An equivalent job exposure matrix for exposure to arsenic trioxide and other arsenic compounds is not available at present but it is known that arsenic compounds were an important constituent of the incoming feedstocks. Lamm et $a l^{6}$ provided summaries that showed that the annual mean percentage of arsenic in feedstocks for the plant in the period 1926-39 ranged from $2 \%$ to $10 \%$. The corresponding range for the period $1940-58$ was $1 \%-4 \%$. It is also known that exposure to arsenic compounds were much higher in the early process departments (sampling, mixing, roasting, baghouse, calcine, welders and burners) than the other departments (retort, casting, solution, tankhouse, pigment). For example, Thun et $a^{3}$ provide results of arsenic measurements from 1973 in which concentrations of 0.3 and $1.1 \mu \mathrm{g} . \mathrm{m}^{-3}$ were found in the premelt (casting) department and a concentration of $1.4 \mu \mathrm{g} . \mathrm{m}^{-3}$ was found in the retort department. These values may be compared with airborne arsenic concentrations ranging from $300-700 \mu \mathrm{g} \cdot \mathrm{m}^{-3}$ near the roasting and calcine furnaces in 1950 (about $100 \mu \mathrm{g} \cdot \mathrm{m}^{-3}$ in 1979).

\section{POISSON REGRESSION}

Several variables were considered to have the potential for influencing mortality within the cohort: age attained (age at follow up or age at death), year of starting employment, Hispanic ethnicity, estimated cumulative exposure to cadmium, estimated cumulative exposure to cadmium in the presence of exposure to arsenic trioxide, estimated cumulative exposure to cadmium in the absence of arsenic trioxide exposure, and ever being employed in the arsenic department. These variables were not treated as continuous variables, but each variable was categorised into several levels. In constructing the models, it was necessary to ensure that there was at least one death at each level of each variable. Any adjustments were made before any statistical modelling was carried out. Age attained and estimated cumulative exposures to cadmium are time dependent variables and the analysis allowed, therefore, for subjects to contribute person-years at risk to contemporaneous categories.

Analyses were also carried out with exposures lagged by 10 (and 20 years) - that is, exposures were assumed to have no effect until 10 (or 20) years had elapsed. This procedure was accomplished by adding 10 (or 20) years to the dates of transition from one exposure category to another. (Thus a worker who accumulated $400 \mathrm{mg} \cdot \mathrm{m}^{-3}$.days of exposure to cadmium on 10 January 1951, would not accumulate this amount of exposure lagged by 10 years until 10 January 1961 .)

The epicure ${ }^{13}$ computer program was used to provide person-years at risk, numbers of deaths from lung cancer, and numbers of deaths from all causes excluding lung cancer for all combinations of all levels of the selected variables. Study subjects entered the personyears at risk when six months of employment had been completed or on 1 July 1940, whichever was the later, and left the personeach study subject to find if and when any of these cut offs for cumulative exposures were reached. 
Table 4 Mortality from lung cancert and all other causes $\neq$ by levels of cumulative exposure to cadmium (unlagged and lagged exposures), 1940-82

\begin{tabular}{|c|c|c|c|c|c|c|}
\hline \multirow{2}{*}{$\begin{array}{l}\text { Cumulative exposure to } \\
\text { cadmium }\left(\mathrm{mg}^{2} \mathrm{~m}^{3} \cdot \text { days }\right)\end{array}$} & \multicolumn{3}{|c|}{ Cancer of lung } & \multicolumn{3}{|c|}{ All other causes } \\
\hline & $n$ & $R R S$ & $(95 \% C I)$ & $n$ & $R R \int$ & $(95 \% C I)$ \\
\hline \multicolumn{7}{|l|}{ Unlagged: } \\
\hline$<400$ & 6 & $1 \cdot 0$ & & 102 & $1 \cdot 0$ & \\
\hline $400-999$ & 6 & $2 \cdot 25$ & $(0 \cdot 72$ to $7 \cdot 02)$ & 38 & 0.92 & $(0.63$ to 1.33$)$ \\
\hline $1000-1999$ & 4 & $2 \cdot 41$ & $(0.66$ to 8.72$)$ & 16 & 0.73 & $(0.44$ to 1.21$)$ \\
\hline$\geqslant 2000$ & 5 & $4 \cdot 13^{\star}$ & $(1.21$ to 14.03$)$ & 23 & $1 \cdot 15$ & $(0.70$ to 1.89$)$ \\
\hline Evaluation of trend $\pi$ & & $1.56^{\star}$ & $(1.06$ to $2 \cdot 28)$ & & 0.98 & $(0.84$ to $1 \cdot 14)$ \\
\hline \multicolumn{7}{|l|}{ Employment history lagged by 10 years: } \\
\hline$<400$ & 6 & $1 \cdot 0$ & & 113 & $1 \cdot 0$ & \\
\hline 400-999 & 6 & $2 \cdot 73$ & $(0.85$ to 8.74$)$ & 33 & 0.92 & $(0.62$ to 1.37$)$ \\
\hline $1000-1999$ & 5 & $3 \cdot 82^{\star}$ & $(1 \cdot 10$ to $13 \cdot 28)$ & 16 & $0 \cdot 70$ & $(0.41$ to 1.20$)$ \\
\hline$\geqslant 2000$ & 4 & $5 \cdot 67^{\star \star}$ & $(1.48$ to $21 \cdot 77)$ & 17 & $1 \cdot 37$ & ( 0.80 to $2 \cdot 35)$ \\
\hline Evaluation of trend $\pi$ & & $1 \cdot 76^{\star \star}$ & $(1 \cdot 18$ to $2 \cdot 64)$ & & 1.01 & $(0.85$ to 1.19$)$ \\
\hline \multicolumn{7}{|l|}{ Employment history lagged by 20 years: } \\
\hline$<400$ & 9 & $1 \cdot 0$ & & 124 & $1 \cdot 0$ & \\
\hline $400-999$ & 6 & $2 \cdot 55$ & $(0.86$ to 7.60$)$ & 29 & 1.05 & $(0.69$ to 1.61$)$ \\
\hline $1000-1999$ & 3 & 2.57 & $(0 \cdot 64$ to $10 \cdot 27)$ & 15 & $1 \cdot 03$ & $(0.58$ to 1.81$)$ \\
\hline$\geqslant 2000$ & 3 & $7 \cdot 33^{\star \star}$ & (1.83 to 29.47 ) & 11 & $2 \cdot 20^{\star}$ & $(1 \cdot 16$ to $4 \cdot 21)$ \\
\hline Evaluation of trendT & & $1 \cdot 83^{\star}$ & $(1.19$ to 2.82$)$ & & $1 \cdot 17$ & $(0.96$ to 1.42$)$ \\
\hline
\end{tabular}

$\star P<0.05 ;{ }^{\star} \star \mathrm{P}<0.01$

tLung cancer (ICD-8: 162, 163) mentioned in any part of the death certificate.

fAll deaths for which the death certificate did not mention lung cancer (ICD-8: 162-163).

Adjusting for six levels of age attained $(40-54,55-59,60-69,70-74,75-84)$

TRelative risk for change in exposure of one level, obtained by treating cumulative exposure as a continuous variable coded $1,2,3$, or 4 for the four levels of exposure.

years at risk on the date of death or 31 December 1982, whichever was the earlier. The epicure program was also used to carry out statistical modelling by means of Poisson regression. ${ }^{14}$ The purpose of the modelling was to establish whether the mortality experienced by the study cohort, and in particular the mortality experienced by the different cumulative exposure groups, could be described easily in terms of variables such as age attained and year of starting employment (covariates), or whether the inclusion of the variable cumulative exposure to cadmium made a significant contribution to the ability of the overall model to describe the data. The significance of this contribution was assessed by the likelihood ratio test comparing deviance and degrees of freedom with and without inclusion of the variable cumulative exposure to cadmium Also, the significance of any trend in risk across the four exposure categories was assessed by repeating the analysis while treating cumulative exposure as a continuous variable coded $1,2,3$, or 4 for the four levels of exposure.

At the outset of this analysis, cancer of the lung (eighth revision of the international classification of diseases (ICD-8) codes 162-163) was selected for further study. Cases were selected as those deaths for which any part of the death certificate (1a, 1b, 1c, or II) would be coded to the above categories. Occupational exposure to cadmium was not expected to have a discernible influence on many causes of death. Consequently, mortality from all causes excluding lung cancer (as defined above) was also studied to assess the usefulness of the explanatory variables used in the statistical models. Each analysis was carried out on the totality of deaths for the cause under investigation.

\section{Results}

Table 4 provides relative risks of lung cancer and all other causes by levels of estimated cumulative exposures to cadmium (unlagged exposures, exposures lagged by 10 years, exposures lagged by 20 years). Findings from these six separate analyses were complemented by summaries of six further analyses which assessed the significance of any trends of risk across the four levels of exposure. For each analysis, cumulative exposure to cadmium was analysed simultaneously with age attained (six levels: 40-54, 55-59, 60-64, $65-69,70-74,75-84)$. The inclusion of the variable cumulative exposure to cadmium made a significant improvement to the models for lung cancer; there were notably increased relative risks for this cause of death. Although based on small numbers of deaths, the trends were more pronounced when exposures were lagged. The inclusion of the variable cumulative exposure to cadmium did not approach a significant improvement to the models for all causes excluding lung cancer; relative risks for this group of deaths were close to unity.

Table 5 shows the role of two potential confounding variables on risk estimates for lung cancer and for all other causes combined. The left hand side of the table provides point estimates of relative risk for different cumulative exposures to cadmium, year of hire, and Hispanic ethnicity when these three variables were analysed separately, and the right hand side of the table provides similar estimates when the three variables were analysed simultaneously. These relative risks were obtained from eight separate analyses; table 5 also summarises a further four analyses which assessed the significance of any trends of risk across the four levels of cumulative exposure to cadmium. Workers of Hispanic ethnicity had much lower risks of lung cancer than other members of the cohort although the difference in the two groups of workers did not reach significance. However, in this study Hispanic ethnicity was not a confounding variable in the analysis of risks of lung cancer and cumulative exposure to cadmium because the point estimates of risk are little changed when simultaneous adjustment was made for Hispanic ethnicity (right hand part of table 5). Year of 
Table 5 Mortality from lung cancert and all other causes $\neq$ by cumulative cadmium exposure with and without adjustment for two potential confounding variables, 1940-82

\begin{tabular}{|c|c|c|c|c|c|}
\hline \multirow[b]{2}{*}{ Variable with levels } & \multicolumn{3}{|c|}{ Separate analysis } & \multicolumn{2}{|c|}{ Simultaneous analysis } \\
\hline & $n$ & $R R S$ & $(95 \% C I)$ & $R R \int$ & $(95 \% C I)$ \\
\hline \multicolumn{6}{|l|}{ Cancer of lung: } \\
\hline \multicolumn{6}{|c|}{ Cumulative exposure to cadmium (mg.m ${ }^{-3}$.days): } \\
\hline$<400$ & 6 & $1 \cdot 0$ & & $1 \cdot 0$ & \\
\hline $400-999$ & 6 & $2 \cdot 25$ & $(0.72$ to 7.02$)$ & $2 \cdot 30$ & $(0.72$ to 7.36$)$ \\
\hline $1000-1999$ & 4 & $2 \cdot 41$ & $(0.66$ to 8.72$)$ & $2 \cdot 83$ & $(0.75$ to $10 \cdot 72)$ \\
\hline$\geqslant 2000$ & 5 & $4 \cdot 13^{\star}$ & $(1.21$ to 14.03$)$ & $3 \cdot 88^{\star}$ & $(1.04$ to 14.46$)$ \\
\hline Evaluation of trend $\pi$ & & $1 \cdot 56^{\star}$ & $(1.06$ to $2 \cdot 28)$ & $1 \cdot 58^{\star}$ & $(1.03$ to 2.30$)$ \\
\hline \multicolumn{6}{|l|}{ Year of hire: } \\
\hline $1926-33$ & 3 & $1 \cdot 0$ & & $1 \cdot 0$ & \\
\hline $1934-39$ & 5 & 1.02 & $(0 \cdot 24$ to $4 \cdot 27)$ & $1 \cdot 26$ & $(0 \cdot 30$ to $5 \cdot 42)$ \\
\hline $1940-49$ & 10 & 0.42 & $(0.11$ to 1.51$)$ & 0.93 & $(0.23$ to 3.75$)$ \\
\hline $1950-69$ & 3 & 0.45 & (0.09 to 2.29$)$ & 1.07 & $(0 \cdot 18$ to $6 \cdot 18)$ \\
\hline \multicolumn{6}{|l|}{ Hispanic ethnicity: } \\
\hline Yes & 4 & $1 \cdot 0$ & & $1 \cdot 0$ & \\
\hline No & 17 & $2 \cdot 73$ & $(0.92$ to $8 \cdot 12)$ & $2 \cdot 68$ & $(0.81$ to 8.85$)$ \\
\hline \multicolumn{6}{|l|}{ All other causes: } \\
\hline \multicolumn{6}{|c|}{ Cumulative exposure to cadmium (mg.m '.days): } \\
\hline$<400$ & 102 & $1 \cdot 0$ & & $1 \cdot 0$ & \\
\hline $400-999$ & 38 & 0.92 & $(0.63$ to 1.33$)$ & $0 \cdot 88$ & $(0.60$ to 1.29$)$ \\
\hline $1000-1999$ & 19 & 0.73 & $(0.44$ to 1.21$)$ & 0.77 & $(0.46$ to 1.29$)$ \\
\hline$\geqslant 2000$ & 20 & $1 \cdot 15$ & $(0.70$ to 1.89$)$ & 1.02 & $(0.61$ to 1.72$)$ \\
\hline Evaluation of trendT & & 0.98 & $(0.84$ to 1.14$)$ & 0.96 & $(0.82$ to 1.13$)$ \\
\hline \multicolumn{6}{|l|}{ Year of hire: } \\
\hline $1926-33$ & 19 & $1 \cdot 0$ & & $1 \cdot 0$ & \\
\hline $1934-39$ & 20 & 0.62 & $(0.33$ to 1.17$)$ & $0 \cdot 60$ & $(0.32$ to $1 \cdot 14)$ \\
\hline $1940-49$ & 114 & 0.69 & $(0.43$ to 1.13$)$ & 0.77 & $(0.45$ to 1.31$)$ \\
\hline $1950-69$ & 26 & $0 \cdot 48^{\star}$ & $(0.26$ to 0.87$)$ & $0.51^{\star}$ & $(0.27$ to 0.96$)$ \\
\hline \multicolumn{6}{|l|}{ Hispanic ethnicity: } \\
\hline Yes & 57 & $1 \cdot 0$ & & $1 \cdot 0$ & \\
\hline No & 122 & $1 \cdot 39^{\star}$ & $(1.01$ to 1.90$)$ & 1.38 & $(0.98$ to 1.94$)$ \\
\hline
\end{tabular}

$$
\star \mathrm{P}<0 \cdot 05 \text {. }
$$

Footnotes as for table 4 .

hire was also shown not to confound the relation between risks of lung cancer and cumulative exposure to cadmium.

Table 6 shows relative risks of lung cancer and all other causes by levels of cumulative exposure to cadmium in three different occupational settings: departments with high exposure to cadmium and arsenic compounds (excluding the arsenic department), departments with high exposures to cadmium but minimal or no exposures to arsenic, and other departments. (Cut off values for exposure categories were set to be $50 \%$ of those used in tables 4 and 5.) Also, the role of the binary variable "ever employed in the arsenic depart- ment" was considered (the plant carried out some arsenic recovery work in 1926-30 after the main business of the plant had changed from arsenic recovery to cadmium recovery). These four occupational variables were analysed simultaneously with age attained, year of hire, and Hispanic ethnicity. A significant positive trend was found for risk of lung cancer and cumulative exposure to cadmium in the presence of high exposure to arsenic but not for the other two variables of exposure to cadmium. A point estimate of relative risk of $10 \cdot 25$ was found for lung cancer and ever having been employed in the arsenic department although this finding is based on only one

Table 6 Mortality from lung cancert and all other causes $¥$ by simultaneous analysis of four aspects of occupational histories, 1940-82

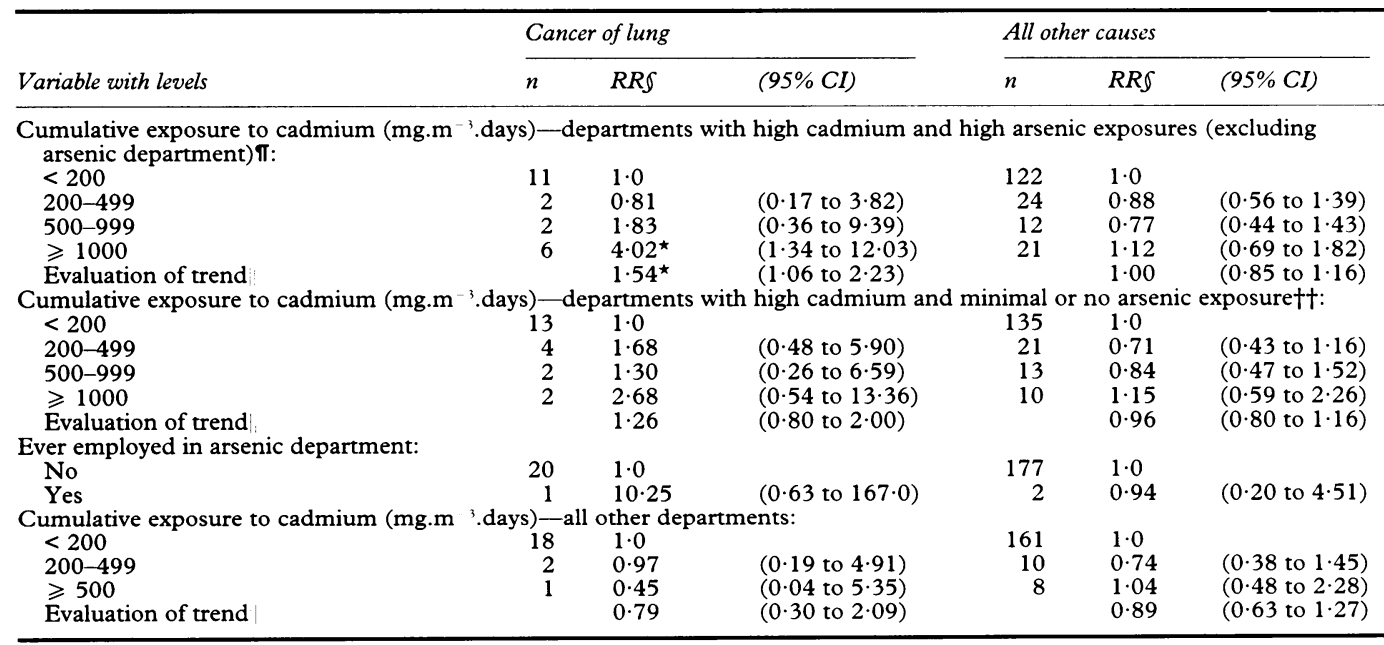

$\star \mathrm{P}<0.05$.

$t, \neq$ As for table 4 .
fWith simultaneous adjustment for six levels of attained age, four levels of year of hire $(1926-33,1934-9,1940-9,1950-69)$ and two levels of hispanic ethnicity (yes or no).

twCalcine, mixer and screener, sampling, roasting, concentrated and dry dust, welder, and burner.

TRelative risk for change in exposure of one level, obtained by treating cumulative exposure as a continuous variable coded 1, 2 , Relative risk for change in exposure
3,4 for the four levels of exposure.

3,4 for the four levels of exposure.
t+Solution (operator and pressman), solution (charger), pigment (gasman), pigment (other operator), tankhouse and electrolytic, retort, caster, crushing. 
Table 7 Mortality from lung cancert and all other causes $\neq$ by simultaneous analysis of two aspects of occupational histories, $1940-82$

\begin{tabular}{|c|c|c|c|c|c|c|}
\hline \multirow[b]{2}{*}{ Variable with levels } & \multicolumn{3}{|c|}{ Cancer of lung } & \multicolumn{3}{|c|}{ All other causes } \\
\hline & $n$ & $R R \int$ & $(95 \% C I)$ & $n$ & $R R \int$ & $(95 \% C I)$ \\
\hline \multirow{2}{*}{\multicolumn{7}{|c|}{ Cumulative exposure to cadmium (mg.m ${ }^{3}$.days) - departments with high arsenic exposures (including arsenic department) $\pi$ : }} \\
\hline & 10 & $1 \cdot 0$ & & 122 & 1.0 & \\
\hline $200-499$ & 3 & $1 \cdot 29$ & $(0.34$ to 4.83$)$ & 24 & 0.78 & $(0.50$ to 1.22$)$ \\
\hline $500-999$ & 2 & 1.92 & $(0.38$ to $9 \cdot 75)$ & 12 & $0 \cdot 80$ & $(0.43$ to 1.48$)$ \\
\hline$\geqslant 1000$ & 6 & $3 \cdot 85^{\star}$ & $(1.28$ to $11 \cdot 56)$ & 21 & $1 \cdot 12$ & $(0.69$ to 1.83$)$ \\
\hline Evaluation of trend & & $1.52^{\star}$ & $(1.06$ to 2.19$)$ & & 0.99 & $(0.85$ to 1.16$)$ \\
\hline \multicolumn{7}{|c|}{ Cumulative exposure to cadmium (mg.m ${ }^{-3}$.days) - all other departments: } \\
\hline$<200$ & 11 & $1 \cdot 0$ & & & $1 \cdot 0$ & \\
\hline $200-499$ & 5 & 1.45 & $(0.48$ to 4.39$)$ & 31 & 0.88 & $(0.58$ to 1.31$)$ \\
\hline $500-999$ & 2 & 0.95 & $(0.19$ to 4.74$)$ & 13 & 0.72 & $(0.40$ to 1.31$)$ \\
\hline$\geqslant 1000$ & 3 & 1.75 & $(0.44$ to 6.96$)$ & 19 & $1 \cdot 17$ & $(0.69$ to 1.98$)$ \\
\hline Evaluation of trend & & $1 \cdot 13$ & $(0.74$ to 1.73$)$ & & 0.97 & $(0.82$ to 1.14$)$ \\
\hline
\end{tabular}

observed death. Findings for all other causes combined are unexceptional.

Table 7 shows relative risks of lung cancer and all other causes by levels of cumulative exposure to cadmium received in two different occupational settings: departments with high exposure to arsenic compounds and all other departments. These two occupational variables were analysed simultaneously with adjustment for age attained, year of hire, and Hispanic ethnicity. A significant positive trend was found for risk of lung cancer and cumulative exposure to cadmium received in the presence of high exposure to arsenic but not for cumulative exposure to cadmium received in the absence of high exposure to arsenic. Findings for all other causes combined are unexceptional.

An independent assessment was sought of the likely reliability of the estimates of cumulative exposure to cadmium used in this report by comparing estimates of individual cumulative exposure to cadmium with in vivo measurements of cadmium in liver from the same people. In a study of 82 workers from the plant under study here, Ellis et al ${ }^{12}$ had, for a subset of 51 workers currently employed in 1979 (active workers), found a good correlation $(r=0.70, \mathrm{P}<0.001)$ between measurements of liver cadmium obtained from neutron activation analysis and estimates of cumulative exposure to cadmium based on employment histories (collected by Ellis et al) and the job exposure matrix (table 2). A total of 29 of these 51 workers are members of the mortality study cohort; the Spearman rank correlation coefficient between the in vivo measurements of cadmium in liver and estimated cumulative exposures to cadmium (new data) for these 29 workers was only $0 \cdot 13$ $(\mathbf{P}<0 \cdot 2)$. A similarly poor correlation was obtained between the in vivo measurements of cadmium in liver and the cumulative exposures to cadmium estimated by Thun et $a l^{3}$ ( $r$, $=0 \cdot 11, \mathrm{P}<0 \cdot 2$ ).

\section{Discussion}

In the reanalysis of these cohort mortality data we sought to obtain more reliable information for the identification and measurement of any risks of lung cancer arising from occupational exposures to cadmium by correcting some potentially serious errors in the data on job histories analysed previously, re-estimating cumulative exposures to cadmium, and enabling a fuller evaluation of the potentially confounding role of exposure to arsenic compounds. We re-assessed individual estimates of cumulative exposures to cadmium (as a time dependent variable) by applying the job exposure matrix used in previous analyses to more accurate data on job histories.

The new analysis shows a significant positive trend of risk of lung cancer with levels of cumulative exposure to cadmium. This relation cannot be explained by confounding effects of year of hire or Hispanic ethnicity. Also, this relation became more pronounced when the exposures were lagged by 10 or 20 years. This contrasts with the analysis of Stayner et $a l,{ }^{5}$ in which the estimates of the effects of exposure to cadmium were reduced when the exposures were lagged by more than five years. The new overall findings provide, therefore, more convincing evidence of occupational risks of lung cancer caused or associated with exposures to cadmium.

More complex analyses were carried out in an attempt to disentangle the effects of exposures to cadmium received in the presence or absence of high exposure to arsenic compounds. Significant trends were obtained only for risks of lung cancer and exposures to cadmium received in the presence of high exposure to arsenic.

These data have limitations. Data on histories of smoking were not available for the entire cohort and the available data on smoking were not incorporated into the analysis. It is not possible to predict how adjustment for accurate and complete information on smoking would influence the occupational findings. The earlier entry cohorts may have differed from the later entry cohorts in their smoking habits. However, such general putative differences cannot offer an explanation for the occupational findings because year of hire was shown not to be an important confounding variable in the occupational analyses.

A further limitation is the lack of independent evidence of the reliability of the individual estimates of cumulative exposure to cadmium. Such evidence was not provided by a 
comparison of these estimates with in vivo measurements of cadmium in liver. This was disappointing given that quite good correlations have been found between these two variables in several studies. ${ }^{12}{ }^{16-18}$ However, the very different findings provided by Ellis et al ${ }^{12}$ and this report for cadmium in liver and cumulative exposures to cadmium can be reconciled. Ellis et al state: "As could be expected, the active workers with lower exposure histories were also those with the lower liver burdens. For example, the eight workers employed for less than one year at the plant had ... liver cadmium values... within the normal range". ${ }^{12}$ By definition, these employees (and other employees who started employment with the company after 1969 also tended to have low concentrations of cadmium in the liver) could not be members of the cohort studied here and data for these employees were influential in the correlations reported by Ellis et al. ${ }^{12}$ Some readers may be under the impression that the NIOSH estimates of cumulative exposure have already been validated by a comparison with in vivo data but the comment "a strong correlation was found between the calculated cumulative exposure, and the Brookhaven measurement of liver cadmium, ..." must relate to the data on job histories collected by Ellis et al ${ }^{12}$ and not the data on job histories collected by Thun et al. ${ }^{3}$

These (and other) analyses are limited by the non-availability (to date) of follow up particulars for those employees who left employment before 1940 . For example, only a small proportion of those employees first employed in the 1920s probably appear in the cohort as defined and unmeasured selection effects may be operating on the employees available for study.

Interpretation of the study findings is made more difficult given that the estimates of exposure to cadmium by inhalation provided in the job exposure matrix (table 2) do not all refer to cadmium oxide, fume, or dust. Moreover, exposures to cadmium sulphate and cadmium sulphide tended to occur in the absence of high exposure to arsenic compounds whereas exposures to cadmium oxide tended to occur in the presence of high exposures to arsenic trioxide. Consequently, several hypotheses have been identified which are consistent with the study findings: (a) cadmium oxide in the presence of arsenic trioxide is a human lung carcinogen, $(b)$ cadmium oxide and arsenic trioxide are human lung carcinogens and cadmium sulphate and cadmium sulphide are not (or they are less potent carcinogens), or (c) arsenic trioxide is a human lung carcinogen ${ }^{15}$ and cadmium oxide, cadmium sulphate, and cadmium sulphide are not. Given the few lung cancer deaths available for this analysis it is impossible to gauge which, if any, of the above hypotheses is correct. Findings from other studies $^{8}$ must be considered together with the recent findings of mortality among a cohort of United Kingdom copper-cadmium alloy workers. ${ }^{18}$ These recent findings do not support the hypothesis that cadmium oxide fume is a human lung carcinogen.
Confident interpretation of the data from the United States may become possible when further follow up data become available (follow up data for this analysis were only available to the end of 1982). Confident interpretation would also be assisted by incorporating a quantitative job exposure matrix for exposure to arsenic compounds into the analyses. Other analyses of these mortality data are encouraged to make use of the extraordinarily detailed data on job histories available.

We thank Jaswant Bal and Suvineetha Wanasundara for the dedication and concentration required to abstract voluminous job histories from microfilmed records. We thank Margaret Williams for word processing. This analysis would not have been possible without a research award from the International been possible without a research award from the International ous financial support from the Colt Foundation. We thank the ous financial support from the Colt Foundation. We thank the company management for access to company records and cur-
rent and former company staff (Don Robbins, Curt Pugh, and rent and former company staff (Don Robbins, Curt Pugh, and
Steve Stephens) for invaluable help in making sense of the job Steve Stephens) for invaluable help in making sense of the job
descriptions. We thank Drs Keith Ellis and Wyn Morgan for descriptions. We thank Drs Keith Ellis and Wyn Morgan for permission to access the in vivo data. We thank Steven Lamm
for encouraging debate about survey data as well as survey findings. We thank Karen Grumski from $\mathrm{CEOH}$ for preparation and description of several complex computer files. We than Malcolm Harrington and David Gompertz for criticisms of an earlier draft; responsibility for the final draft remains with the authors.

1 Lemen RA, Lee JS, Wagoner JK, Blejer HP. Cancer mortality among cadmium production workers. Ann NY Acad Sci 1976;271:273-9.

2 Varner MO. Updated epidemiologic study of American cadmium smelter workers. In: Edited proceedings of the cadmium smelter workers. In: Edited proceedings of the fourth international cadmium conference,

3 Thun MJ, Schnorr TM, Smith AB, Halperin WE, Lemen RA. Mortality among a cohort of US cadmium production workers -an update. I Natl Cancer Inst 1985;74 $325-33$

4 Lamm SH. Analysis of mortality studies of Globe, Colorado cadmium workers. In: Edited proceedings of the fifth international cadmium conference, San Francisco. London: Cadmium Association, 1988:120-3.

5 Stayner L, Smith R, Thun M, Schnorr T, Lemen R. A dose-response analysis and quantitative assessment of lung cancer risk and occupational cadmium exposure. Ann Epidemiol 1992;2:177-94.

6 Lamm SH, Parkinson M, Anderson M, Taylor W. Determinants of lung cancer risk among cadmiumDeterminants of lung cancer risk among cadm

7 Doll R. Is cadmium a human carcinogen? Ann Epidemiol 1992;2:335-7.

8 International Agency for Research on Cancer. LARC Monographs on the evaluation of the carcinogenic risk of chemicals to humans. Vol 58. Beryllium, cadmium, mercury, and exposures in the glass manufacturing industry. Lyon: IARC, 1993.

9 Sorahan T, Lancashire R. Lung cancer findings from the NIOSH study of United States cadmium recovery workers: a cautionary note. Occup Environ Med 1994;51: 139-40.

10 Smith TJ, Anderson RJ, Reading JC. Chronic cadmium exposures associated with kidney function efforts. $A m \mathcal{F}$ Ind Med 1980;1:319-37.

11 Smith TJ, Ferrell WC, Varner MO, Putnam RD. Evaluation of personal exposures of cadmium workers: effects of respirator usage and correlation of exposure effects of respirator usage and correlation of exposure
with urinary excretion. Am Ind Hyg Assoc $\mathcal{7} 1980 ; 41$ : with uring

12 Ellis KJ, Cohn SH, Smith TJ. Cadmium inhalation exposure estimates: their significance with respect to kidne and liver cadmium burden. $\mathcal{F}$ Toxicol Environ Health 1985;15:173-87.

13 Epicure. Hirosoft International Corporation, Seattle, USA

4 Breslow NE, Day NE. Statistical methods in cancer research. Vol II-The design and analysis of cohort studies. Lyon: International Agency for Research on Cancer, 1987. (IARC sci publ No 82.)

15 International Agency for Research on Cancer. LARC Monographs on the evaluation of the carcinogenic risk of chemicals to humans. Vol 23. Some metals and metallic comchemicals to humans. Vol 23.

16 Roels HA, Lauwerys RR, Buchet J, Bernard A, Chettle DR Harvey TC. In vivo measurements of liver and kidney cadmium in workers exposed to this metal. Its significadmium with respect to cadmium in blood and urine. Environ Res 1981;26:217-40.

17 Davison AG, Fayers PM, Newman Taylor AJ, Venables KM, Darbyshire J, Pickering CAC, et al. Cadmium fume inhalation and emphysema. Lancet 1988;i:663-7.

18 Sorahan T, Lister A, Gilthorpe MS, Harrington JM Mortality of copper cadmium alloy workers with specia reference to lung cancer and non-malignant diseases of the respiratory system, 1946-92. Occup Environ Med 1995;52:804-12. 